\title{
GENESIS AND EVOLUTION OF THE SQUARE SODA STRAWS OF DRY CAVE, WEST VIRGINIA, USA
}

\author{
Paolo Forti ${ }^{1}$ and Gregory S. Springer ${ }^{2}$
}

\begin{abstract}
A completely new (sub)type of calcite stalactite, similar to a soda straw but showing an external square shape, has been recently observed within Dry Cave, West Virginia, USA. Though rare speleothems with one or more planar sides (triangular to hexagonal cross sections) have been described in the past, this is the first reported example of a subaerial stalactite-like speleothem with a rhombic parallelepiped structure. More than a dozen examples were observed in the cave. The suggested genetic mechanisms allowing the atypical growth of a parallelepiped seem to be controlled by several boundary conditions that normally preclude their development. Constrained by the specifics of calcite crystallization in descending vadose waters and the morphology of collected (already broken) samples, we hypothesize that an initial very low supersaturation within the feeding tube, together with relatively fast dripping, causes the growth of a normal monocrystalline calcite soda straw with the $C$ axis coincident with the tubular axis and circular cross sections. Calcite precipitation on the outside of the soda straw is possible only if there is a water film flowing on the straw's external surface. Normally, this external flow will cause the rapid transformation of a tubular straw into a typical, polycrystalline conical stalactite. But in this case, the external feeding film is minimally supersaturated or even absent, which slows epitaxial growth over the pre-existing monocrystalline structure of the soda straw and suppresses radial (polycrystalline) growth of calcite crystals. This induces, in stationary conditions, transformation of the straw into parallel, twinned calcite crystals stacked to form a pyramidal stalactite with rhombic cross sections and an overall tapering angle of $<2^{\circ}$. In the most extreme cases, the soda straws are gradually transformed into a seemingly square monocrystalline parallelepiped. The necessary boundary conditions involve a non-stationary distribution of always scarce supersaturated/undersaturated flow over the soda straw, alternating with periods of simple saturation. The controlling factor for the development of conical, pyramidal, and parallelepiped stalactites seems to be the tapering angle. This just outlined genetic mechanism is speculative and should be experimentally tested. Finally, in the few collected samples of the square straws, this shape is often masked by another development step, which probably became active when they were already broken. This final stage was characterized by a sudden increase in supersaturation of epitaxial water, which induced the deposition of a thin layer of polycrystalline calcite that masks, at least partially, the monocrystalline structure of the speleothem.
\end{abstract}

\section{Introduction}

Speleothems are well-known features of caves that have received considerable scientific attention (see Hill and Forti 1997 and references therein). Nonetheless, as caves are explored and studied in greater detail, it is still possible to detect a completely new type of speleothem, or more often, to observe an unreported variant of an already known speleothem type. This is what occurred during a 2016 survey trip, led by Springer, in Dry Cave, West Virginia, USA. Strange, unusually shaped soda straws were observed for the first time in the world. These speleothems exhibit external square surfaces, whose cross sections are notable for their four sharp corners instead of normal round cross sections (Springer, 2019) that is common elsewhere in this cave and throughout the world. Monocrystalline speleothems (stalactites, stalagmites, columns, helictites etc.) with one or more planar sides are very rare, but do exist (Halliday, 1959; Basset and Basset, 1962; Hill and Forti, 1997), but square soda straws were previously unknown. A few fragments of these speleothems (already broken and laying on the floor) were collected in July 2019 for analysis to understand the mechanisms that allowed the evolution of these peculiar soda straws. In the present paper, possible genetic mechanisms for the evolution of these newly reported speleothems is presented on the basis of on-site observations and microscopy results, after a brief morphological description of the still growing square soda straws and naturally broken fragments.

\section{Location}

Dry Cave is in eastern Greenbrier County, West Virginia, USA (Fig. 1A) and developed under the eastern slopes of Beaver Lick Mountain, a NE-SW trending anticlinal ridge. The cave is developed in the Silurian-age Tonoloway Limestone, which has a thickness of 76 meters and is a generally thin-bedded, calcite-pure micrite containing a few minor shales (Price and Heck, 1939). Dry Cave continues to be explored and surveyed but has a surveyed length of $10.7 \mathrm{~km}$ as of October 2019. The cave is known in the local caving community for its spectacular and abundant speleothems, which include aragonite bushes, $10 \mathrm{~cm}$ scale cave popcorn bushes, helictites, and the full suite of more typical spele-

\footnotetext{
${ }^{1}$ NSS 46644, Italian Institute of Speleology, Via Zamboni 67, 40126 Bologna, Italy. paolo.forti@unibo.it

2 NSS 29328FE, Department of Geological Sciences, Ohio University, Athens, OH, USA. springeg@ohio.edu
} 
othems. Dry Cave is entirely vadose and consists of parallel abandoned stream passages offset along steeply dipping limestones and an active strike-oriented stream passage (Fig. 1B).

The square soda straws are located $\sim 2.8 \mathrm{~km}$ upstream of the entrance near survey station DDF18 (Fig. 1C) in a short segment of a 2- to 4-meters wide and 0.5- to 2-meters high abandoned stream passage immediately overlying a larger relict $5 \times 5$-meter stream passage called the Mystery Trunk. The square straws are growing within and adjacent to dense groups of normal, still developing stalactites and soda straws hanging above a moderately dipping flowstone surface. Broken fragments of square soda straws lay on active calcite flowstone on which a few were slightly cemented. After this paper entered the review process, two additional examples were observed during a survey trip in a nearby passage in October 2019.

The longest still growing square soda straw (Fig. 2A) is over $24 \mathrm{~cm}$ long, $12.7 \mathrm{~mm}$ wide at its attachment (top), and $6.5 \mathrm{~mm}$ wide at its tip, while most of the attached and unbroken ones are between $8 \mathrm{~cm}$ and $12 \mathrm{~cm}$ long. Some of them are square from their attachments to near their tips, while others have their square structure interrupted close to their tips, which maintain the original rounded structure for the last few centimetres. Others behave in an opposite manner, enlarging and becoming squared only in the part close to the tip. Most of the square soda straws are wider at their top and progressively decrease in width towards the tip. A few maintain constant width for most, or even the totality, of their length.

The square soda straws described in greater detail below are euhedral, with monocrystalline forms having rhombic cross sections. The largest single crystals are many centimeters long, which is unusual for speleothems not growing subaqueously. For instance, the well-known giant gypsum crystals of Naica, Mexico grew in hydrothermal waters (García-Ruiz et al., 2007). This naturally raises the question of whether the square soda straws originally formed in a pool that has since drained. However, the host passage ends in 3-m drops into the underlying passage, which precludes pooling. Neither the host passage nor Mystery Trunk show signs of pooling or flooding other than small gour dams and rimstone. Square soda straws have water films or water droplets at their tips and are found within typical stalactites and soda straws, all of which appear to still be growing. The broken fragments of square soda straws lay on active flowstone, so overall evidence implies that the unusual straws are either actively forming or of very recent age.

Six fragments of square soda straws (samples S1 through S6 in Table 1) were taken from the cave floor to be analyzed at the Italian Institute of Speleology. In Table 1, sample S6 is subdivided into two different parts that we designate S6A and B; the upper one is square while the bottom portion still preserves the original rounded structure (Fig. 2B).

\section{Morphologic characteristics of the square soda straws}

The ends of samples S1-S6 are nearly perfectly flat, and inspection of their cross sections reveals that they are rhombic, not square (beside the tip of S6, which is still rounded). As such, the phrase square soda straw is a colloquialism derived from the local caving community, and we use the phrase synonymously with rhombic soda straw. Calcite commonly forms rhombic crystals because of its molecular structure, so it is perhaps not surprising that they have a rhombic structure instead of cubical cross sections.

Samples S1-S6 consist primarily of monocrystalline calcite with the $C$ axis coincident with the soda straw growth axes (Fig. 3A, B). The monocrystalline calcite is overlain by a relatively thin pale yellowish calcite overgrowth (from 0.1 $\mathrm{mm}$ to over $2 \mathrm{~mm}$ thick), which partially masks straw shapes and consists of a layer of polycrystalline calcite with the $C$ axis directed radially (Fig. 3C). Straw cross sections were measured along the natural breakage planes, and their long sides range between $8.1 \mathrm{~mm}$ and $13 \mathrm{~mm}$ in length and the short sides from $5.1 \mathrm{~mm}$ to $9.4 \mathrm{~mm}$ (Table 1). The diameters of their internal and still open feeding tubes are between $0.3 \mathrm{~mm}$ and $5.1 \mathrm{~mm}$.

Optical microscope analyses were performed in the Biological, Geological and Environmental Department (BIGEA) of the University of Bologna and confirmed that the inner structure of all samples consist of monocrystalline calcite. In thin sections made parallel to soda straw axes, small voids are common and always developed along the main cleavage planes together with a few larger, partially rounded or lenticular voids (Fig. 4).

\section{Genetic mechanisms and evolution of normal soda straws}

It is useful to briefly recall the factors ruling the development of normal soda straws before discussing the possible mechanisms allowing the evolution of square soda straws. It is well known that the evolution of tubular soda straws is mainly controlled by drip frequency, which must be fast enough to allow slight supersaturation only in the outer part of the hanging drip; the drop must fall before the entire drop reaches greater supersaturation. In this manner, a thin $(0.1 \mathrm{~mm}$ or slightly greater) ring of calcite is deposited with a diameter of $5.1 \mathrm{~mm}$, corresponding exactly to that of the equilibrium drop before its detachment (Fig. 5B) (Curl, 1973).

The supersaturation normally achieved during speleothem development is just high enough to allow selective competition among the embryonic crystals, so that the tubular structure consists of calcite crystals with all the $\mathrm{C}$ axes parallel to the growing speleothem (White, 1976; Fairchild and Baker, 2012). Moreover, in most occurrences, the supersaturation is low enough to avoid simultaneous development of several crystals; therefore, the structure of a soda straw is often 


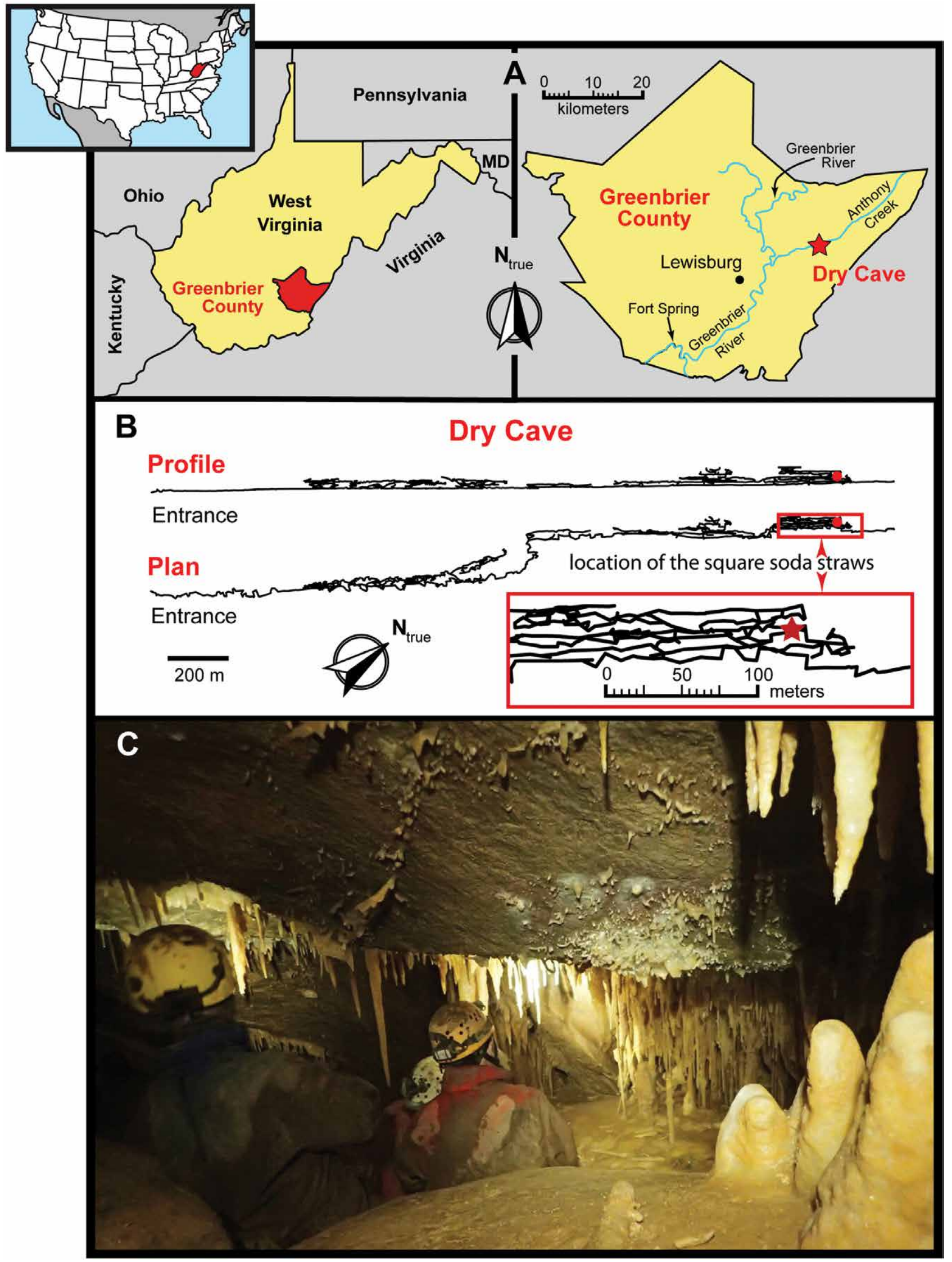

Figure 1. Dry Cave: A: Index map for Dry Cave; B: simplified profile and plan of the cave and location of the square soda straws (red dots and star indicate the survey station DDF18); C: general view of small area near survey station DDF18 in which the square soda straws are restricted. 


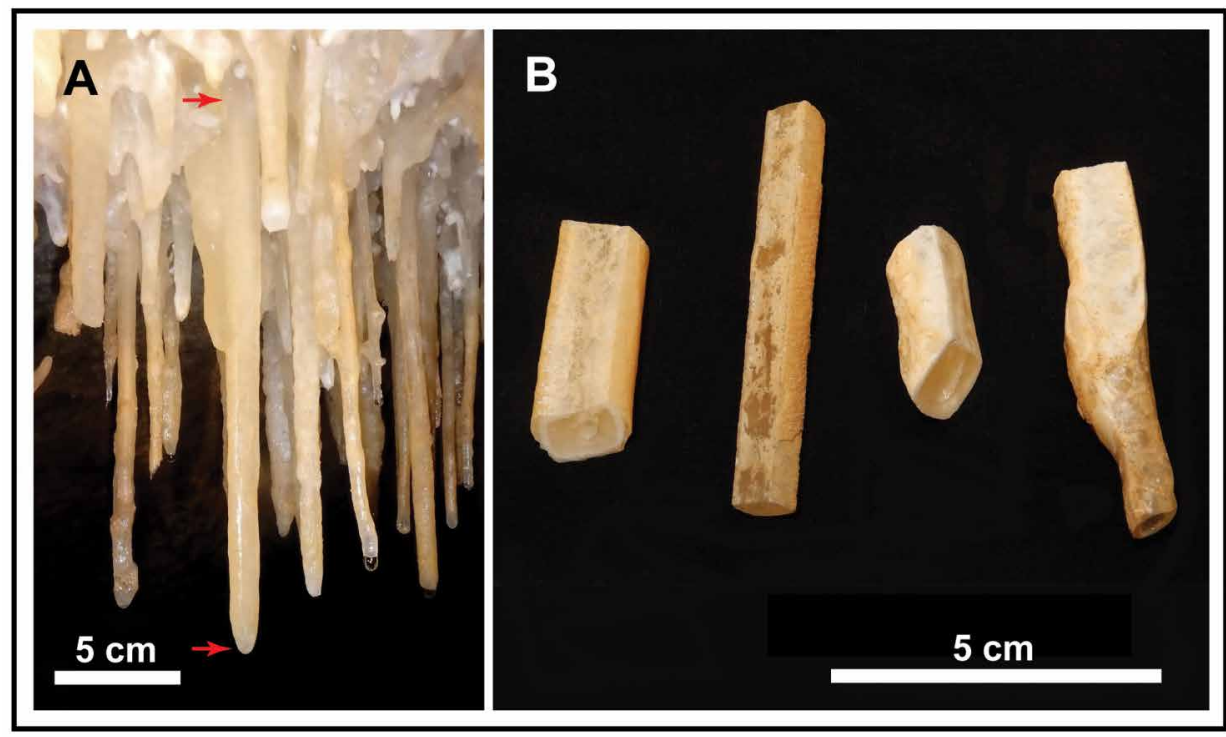

Figure 2. A: The longest still active square soda straw: red arrows point to the top and the tip of the speleothem; B: close-up view of some fragments of the analyzed square straws.

monocrystalline. A true tubular speleothem is expected to have an inner tube with a constant diameter, which is practically the same diameter as the equilibrium drop (Fig. 5B). As drip frequency decreases, supersaturation may increase and progressively extend into deeper portions of the drop. Consequently, calcite deposition occurs not only along the border of the equilibrium drop but also inside (Fig. 5C). This process progressively reduces the diameter of the inner tube, which can eventually become approximately the same size as the original feeding fracture (Fig. 5D).

While dripping ensures the elongation of a soda straw and the size of its internal tube, the increase of its overall diameter can be induced only by water films flowing over the outer surface (White, 1976; Fairchild and Baker, 2012). Several factors affect the evolution of the external shape and internal crystalline structure of a stalactite, including the original supersaturation of the feeding solution, velocity of downward flow, and evaporation and/or condensation processes. In most instances for which approximately constant environmental parameters prevail, the two most import-

Table 1. Dimensions of the cross sections measured on natural breakage surfaces corresponding to the main calcite cleavage planes of the sampled square soda straws. The sample $S 6$ is characterized by a sudden narrowing about $2 \mathrm{~cm}$ from its natural tip with the last portion (S6B) having a quite normal tubular (rounded) form because the transformation into a square one was not yet begun. Long and short side measurements are affected by an experimental error of $0.05 \mathrm{~mm}$ and by the presence of variable but thin (from $0.5 \mathrm{~mm}$ to $1.5 \mathrm{~mm}$ thick) microcrystalline crust covering the calcite monocrystal structure. This uncertainty slightly affects the evaluation of tapering angles.

\begin{tabular}{|c|c|c|c|c|c|}
\hline Sample No. & Length (mm) & $\begin{array}{r}\text { Tapering Angle } \\
\left({ }^{\circ}\right)\end{array}$ & Long side $(\mathrm{mm})$ & Short side (mm) & $\begin{array}{c}\text { Inner tube } \\
\text { diameter (mm) }\end{array}$ \\
\hline $\mathrm{S} 1$ & 112 & 0.3 & $8.65-8.95$ & $5.20-5.35$ & 0.35 \\
\hline $\mathrm{S} 2$ & 93 & $<0.1$ & $8.10-8.20$ & $5.15-5.20$ & $2.95-3.05$ \\
\hline S3 & 85 & 0.3 & $9.15-9.40$ & $5.25-5.40$ & $5.15-3.80$ \\
\hline S4 & 102 & 0.2 & $11.85-12.05$ & $7.70-7.80$ & $3.10-3.30$ \\
\hline S5 & 57 & 0.1 & $12.95-13.00$ & $8.15-8.20$ & 4.25 \\
\hline S6A & 64 & 0.9 & $12.35-12.75$ & $8.80-9.40$ & $4.40-4.50$ \\
\hline S6B & 24 & 0 & 6.45 & 6.24 & 4.90 \\
\hline
\end{tabular}

ant factors are the original degree of supersaturation and the flow rate. The internal crystalline structure is a function of saturation state because it controls precipitation rates (Mullin, 1997) and locations, while flow rate rules the external shape through similar means (Short et al., 2005a, 2005b).

The degree of supersaturation is always the single parameter responsible for the development of a stalactite's crystal structure (Fig. 6). Initially, the stalactite is totally monocrystalline with the $C$ axis coincident with that of the speleothem and the external structure being just an epitaxial growth of the original tubular straw (Fig. 6B). The stalactite subsequently evolves to a clearly banded structure characterized by concentric rings (Fig. 6C-D). Inside each band, the calcite crystals may be organized into palisade structures with the $C$ axes directed radially (Fig. 6C). This occurs when the supersaturation degree is high enough to allow selective competition between crystals with different orientations. But when the supersaturation is very high (often thanks to concomitant evaporation), new nucleation is the ruling process; and therefore, the external rings are characterized by random orientations of $C$ axes (Fig. 6D).

In steady-state conditions, the starting (super)saturation value is constant over time, and thus, cannot affect stalactite tapering because the supersaturated waters do not persist on the stalactite long enough to appreciably change their 

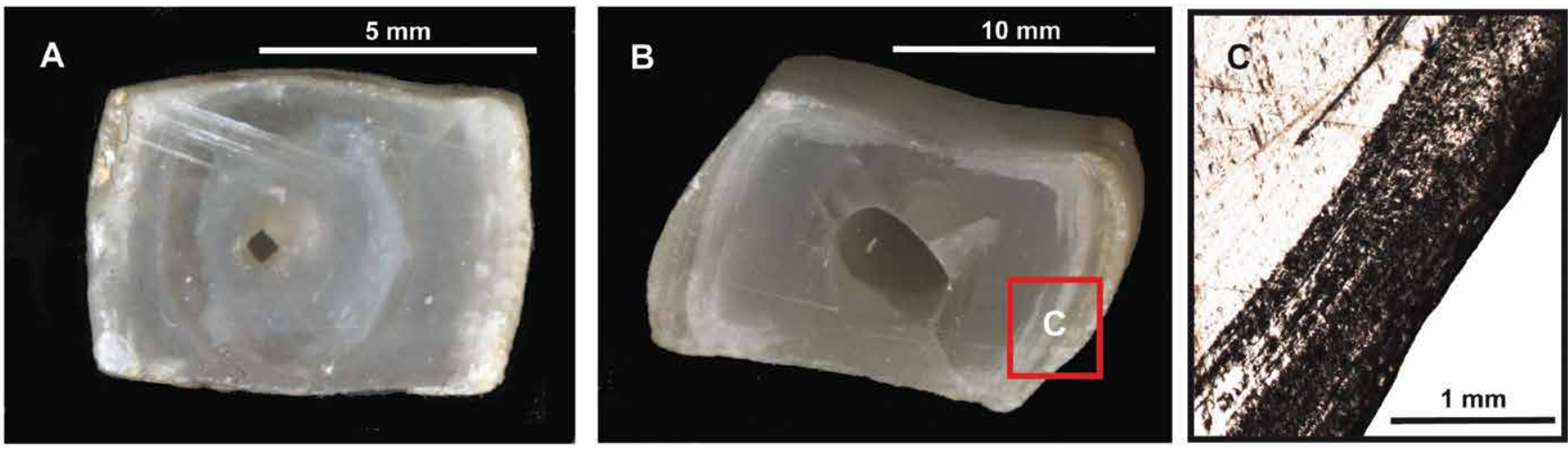

Figure 3. Cross sections of samples S1 (A) and S5 (B, C). A: The inner monocrystal structure of the square soda straws sometime preserve ghosts of the original rounded soda straw, which is particularly evident in S2, where it is also possible to see the effect of re-dissolution and subsequent re-deposition to the left of the inner hole. The central feeding tube has a diameter of $0.35 \mathrm{~mm}$; B: Flat breakage of S5 with evident rhombic structure; C: Polarized microscope image of the thin section where the upper left part of the monocrystalline structure covered by the laminated structure of the polycrystalline layers is clearly visible.

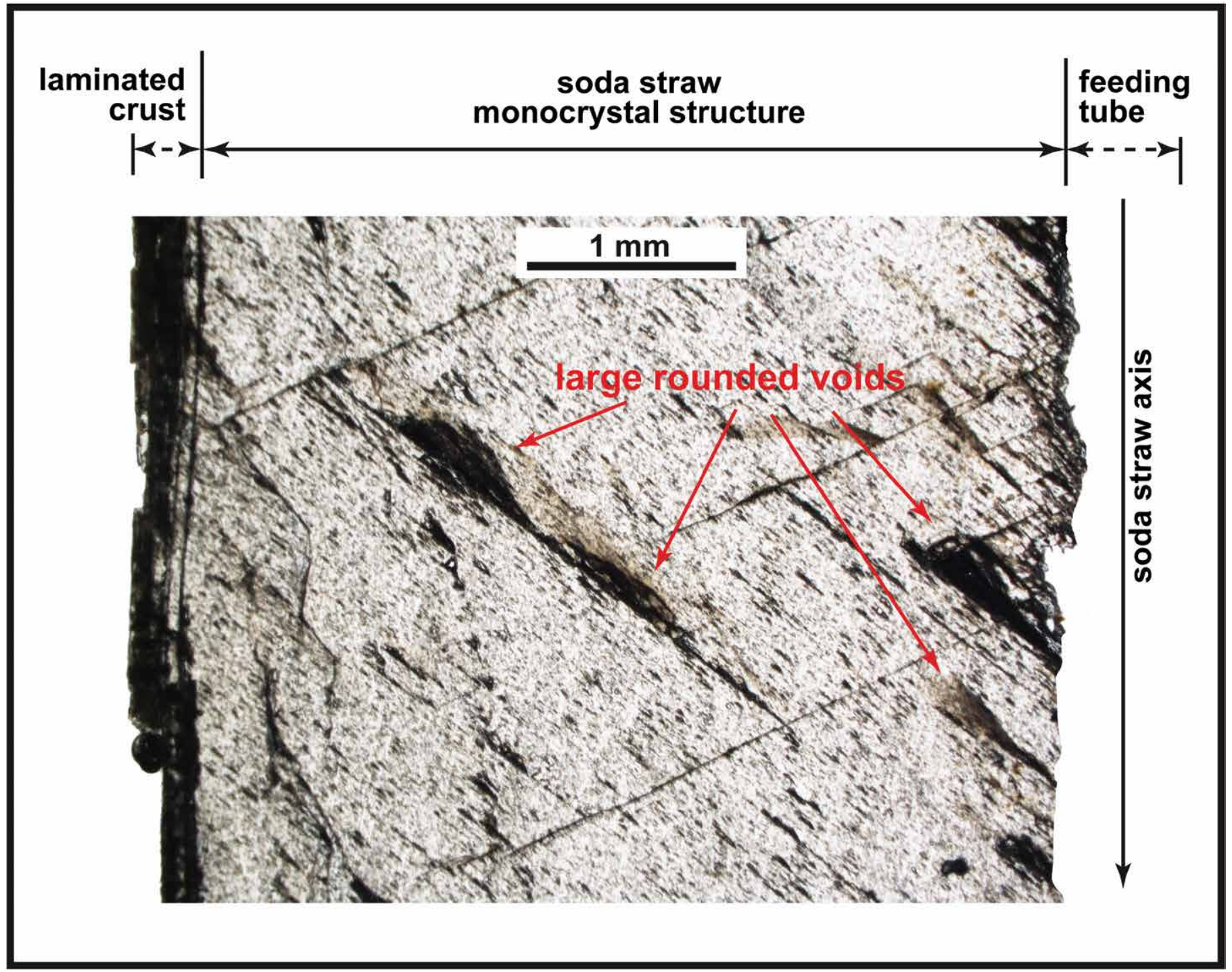

Figure 4. Thin section of the soda straw axis of sample S3. The monocrystal lattice is very rich in voids aligned along the main cleavage planes. A few larger voids exhibit rounded lenticular shapes, suggesting re-dissolution. 


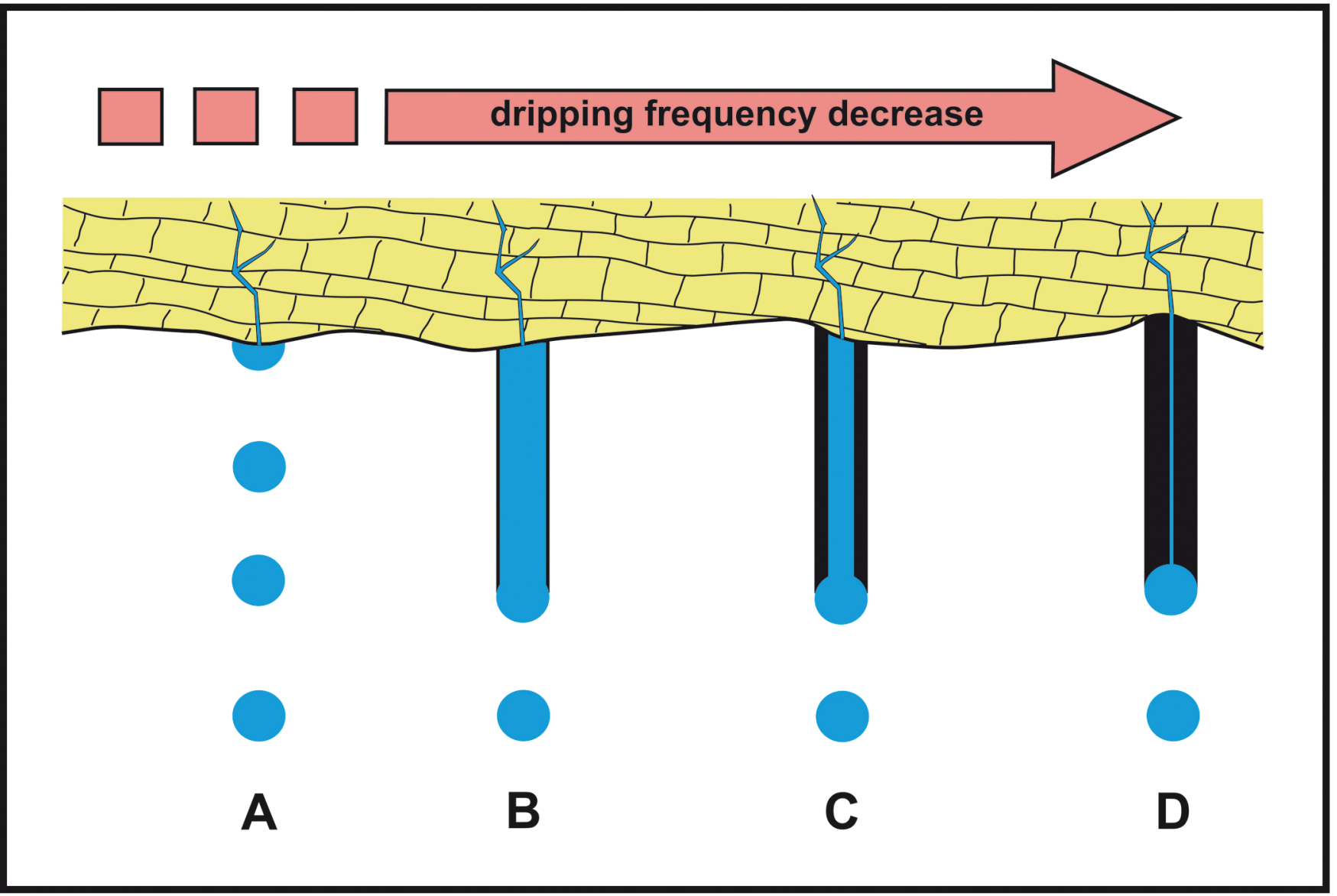

Figure 5. Frequency of dripping and soda straw development. A: the frequency of dripping is too high to allow speleothem growth; B: a feeder tube drips above the limit frequency and therefore creates a normal soda straw with extremely thin external walls; C: a decrease in the drip rate induces a progressive narrowing of the internal tube; D: the internal tube evolves to become the same diameter of the feeding crack below the limit drip frequency.

saturation index via precipitation and degassing of $\mathrm{CO}_{2}$. However, if the amount of water flowing over the speleothem surface is small, the correspondingly slow flow rate allows greater time for precipitation to occur and the saturation index decreases with distance from the attachment point. This enhances tapering because precipitation will be greatest where the saturation index is greatest (Fig. 7).

Thus, from a practical standpoint, in steady-state conditions and in absence of evaporation, the diameter at the top of a stalactite is inversely proportional to the amount of feeding water flowing over it. This is just the opposite of the well-known phenomenon responsible for stalagmite diameters (Franke, 1965). Normal values for the tapering angle (corresponding to the cone vertex angle) of stalactites range between $3^{\circ}$ and $5^{\circ}$, but sometimes the angle can be significantly higher and very rarely it is smaller than $2.5^{\circ}$ (Forti, unpublished experimental measurements). Finally, in steadystate conditions, the progressive decrease in supersaturation along the external surface negates any possibility of the development of perfectly cylindrical or even parallelepiped stalactites (i.e., without tapering).

\section{The mechanism behind the evolution of square soda straws}

The square soda straws are immediately adjacent to typical soda straws and stalactites with round exteriors. Therefore, development of the former cannot solely depend on the meteorology of the area; normal and square soda straws are forming side-by-side and share the same microclimate. Therefore, the controlling factor must be sought mainly in the hydrodynamics or the geochemistry of the feeding waters even if micro-meteorological variations may surely occur due to flow steering and turbulence associated with the many speleothems surrounding the square soda straws. This means condensation and evaporation will vary at multiple spatial and temporal scales, including at the scale of individual speleothems.

Ghosts of circular soda straws contained within the rhombic cross sections of some of the square soda straw fragments show that the first step in their development is the formation of a typical, cylindrical soda straw (Fig. 5). This implies an initial stage of more or less fast dripping of marginally supersaturated water. The measured feeder tubes of the antecedent tubular soda straws never exceed $5 \mathrm{~mm}$, which is also consistent with initial development of a typical soda straw, although one of the observed feeder tubes is $0.35 \mathrm{~mm}$ in diameter. This small diameter may be primary, but 


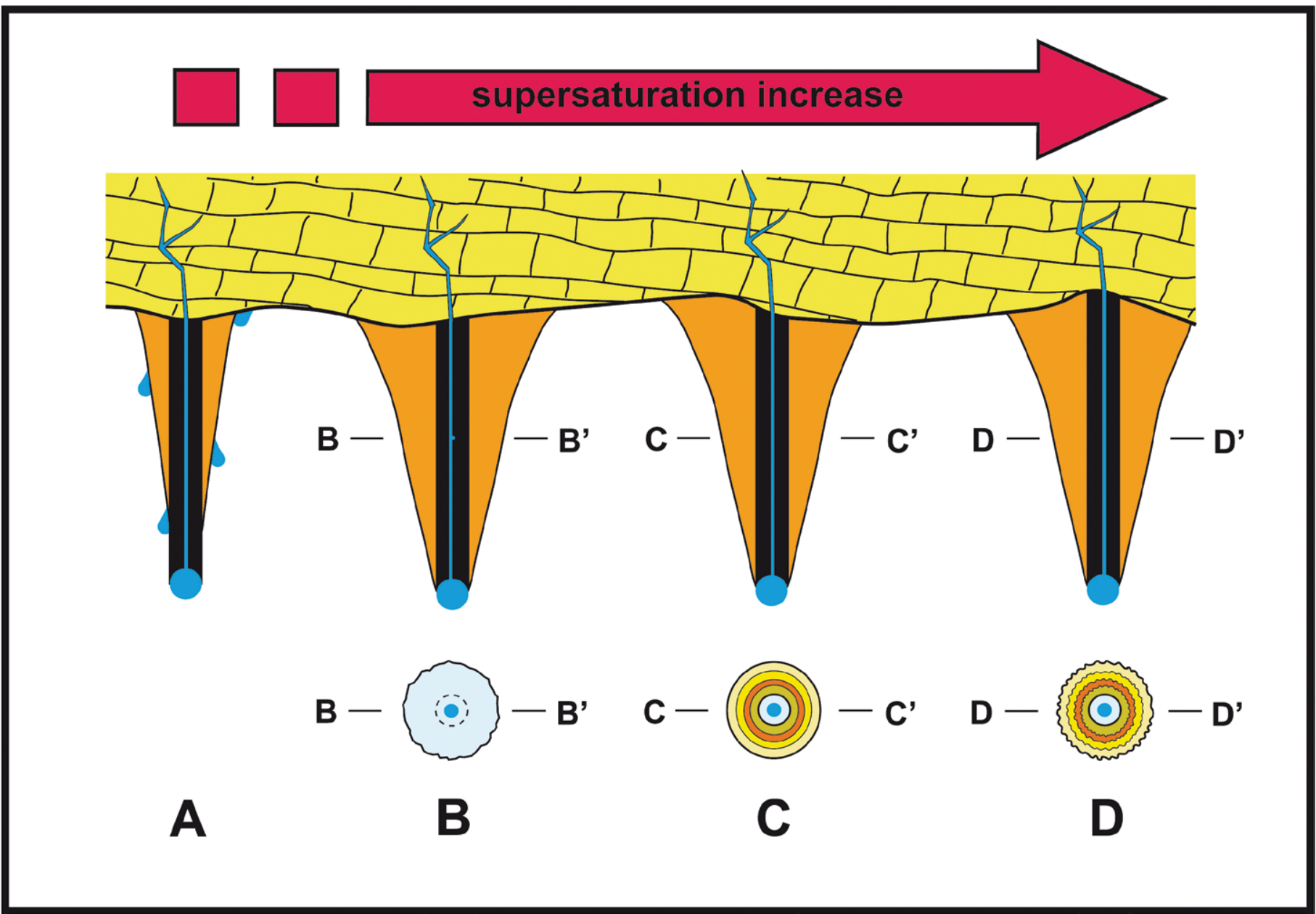

Figure 6. Supersaturation and stalactite crystal structure. A) a soda straw is progressively transformed into a more or less conical stalactite when water starts flowing over its external surface; B) monocrystalline stalactites with $\mathrm{C}$ axis coincident with that of the soda straw form which supersaturation is very low: concentric growth layers are entirely absent in their cross section; C) with higher supersaturation, normal stalactites characterized by smooth concentric growth layers and radial $\mathrm{C}$ axes are formed; $\mathrm{D}$ ) when supersaturation is very high, stalactite growth layers exhibit botryoidal surfaces and completely random $\mathrm{C}$ axis orientations.

it is more likely that the feeder tube gradually became constricted through internal calcite precipitation. This may have occurred after or while the circular straw was forming because actively growing square soda straws were observed to have the same drop diameters as adjacent circular soda straws. Notably, the rhombic shape of active (still attached) square soda straws begins near their attachment points and the square straws taper toward their termini, which are round. For instance, the active $24 \mathrm{~cm}$ long square soda straw is $12.7 \mathrm{~mm}$ wide just below its attachment point and 6.5 $\mathrm{mm}$ wide at its tip (Fig. 8A). This square (pyramidal) stalactite has a tapering angle of about $1.6^{\circ}$.

A round soda straw can only increase in diameter if a water film flows on its external surfaces prior to being squared off. But, as briefly described in the previous paragraph, this is just the very commonly observed process responsible for the evolution of tapering polycrystalline (Fig. 5B) and more rarely, monocrystalline stalactites. Regardless of crystalline structure, such stalactites typically have a tapering angle between 3 and $5^{\circ}$. Therefore, the evolution of square soda straws is clearly an exception to the usual processes at work when soda straws transform into stalactites. But from a theoretical point of view, even if some of them are extremely similar to tubular straws, the square soda straws must be considered a new, peculiar sub-type of stalactite.

It is hard to say if the second, squaring stage was active when the soda straw first began to form or if it started later, when the round soda straw was already at least partially formed. In either case, water began to flow over the outer surface of some tubular straws, thus activating the process of transformation into square stalactites. But why in this occurrence did the soda straws gradually transform themselves into square pyramids (if tapering is present) or parallelepipeds (if tapering is absent) consisting of large rhombic, monocrystalline calcite crystals?

The pyramidal forms consist of a series of euhedral calcite crystals with parallel twinning along the $\mathrm{C}$ axis (Fig.8A), and in every case, the tapering angle (deviation of pyramid sides from orthogonality) is slight in comparison to normal cylindrical stalactites. And some of the analyzed fragments must be considered parallelepipeds because their tapering 


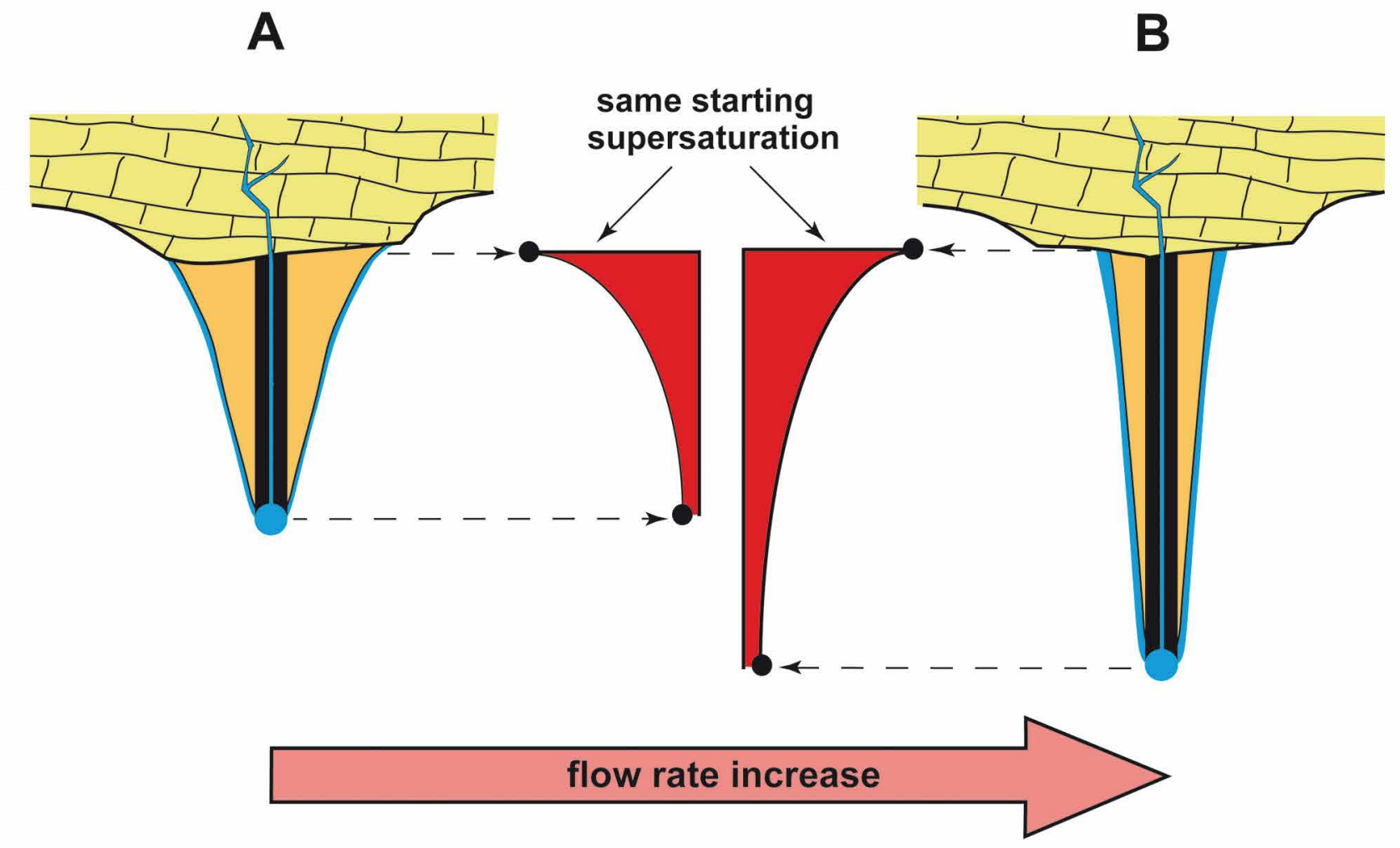

Figure 7. The flow rate on the outside of a stalactite is inversely proportional to the amount of water feeding the speleothem. A slow flow rate allows time for the degree of supersaturation to change because there is more time for precipitation near the attachment point. This favors greater tapering.

angle is less than $0.1-0.3^{\circ}$. Remarkably for a speleothem developing in the open air, these parallelepipeds consist of a single euhedral calcite crystal dramatically elongated along the $\mathrm{C}$ axis (Fig. 8B).

As stated previously, the external form of stalactites is generally a function of the saturation index, and in normal monocrystalline stalactites, the conical overgrowth is characterized by many small sub-euhedral crystals sharing a common crystal lattice structure. The many small crystals reflect sufficient saturation and flow as to allow comparatively rapid, competitive growth from many seeds. Such rapid growth would disrupt growth of large monocrystalline calcite crystals by introducing multiple $\mathrm{C}$ axis orientations. The formation of large euhedral crystals implies largely stable growth conditions such that any variation along the $C$ axis is smoothed out by dissolution and re-precipitation. As discussed below, this would be possible if the water film was only slightly supersaturated because a highly-saturated solution would suppress re-dissolution and allow the misaligned crystals to grow before they could be eliminated to preserve the larger monocrystalline structure (Mullin, 1997).

Measurements of the intact (still attached) square speleothems and the sampled pieces (Table 1) demonstrate a dramatic change in their external shapes, but a relatively small variation in the dimensions of the original soda straws. As already stated, the always constant diameter of a normal soda straw is $5.1 \mathrm{~mm}$ (Curl, 1973), which corresponds to an area of about $26 \mathrm{~mm}^{2}$, while the areas of the square soda straw fragments range between 42 (S2) and $106 \mathrm{~mm}^{2}$ (S5). The longest square straw has an area of $161 \mathrm{~mm}^{2}$ at its attachment point. We nonetheless refer to the square speleothems as straws rather than stalactites because, visually, they more closely resemble soda straws than conical stalactites, especially those that are still attached to the cave ceiling.

The area in which the square soda straws developed is relatively far from the cave entrance, and the local microclimate is presumably very stable with temperatures and humidity decoupled from the entrance region and surface. This would allow relatively long intervals characterized by rather steady water fully saturated with respect to calcite. Therefore, the transformation from rounded to square was mainly induced by the solution-redeposition and recrystallization of the already formed speleothem, while the precipitation of new calcite played a second-order role. The recrystallization responsible for the ghost straws in the broken samples is further evidence for transformation of a pre-existing soda straw. 


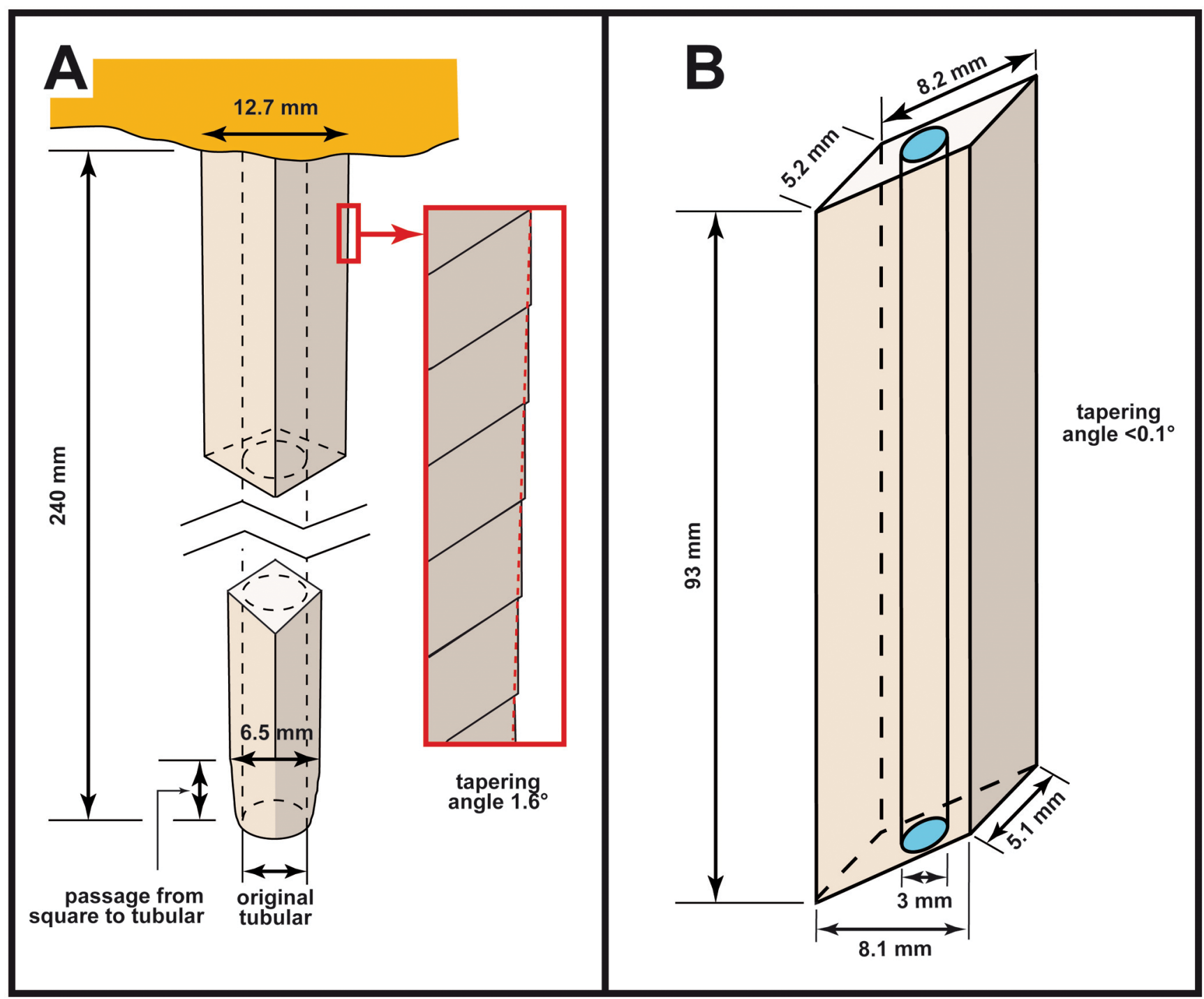

Figure 8. A: drawing of the longest attached square soda straw growing from the cave ceiling. The inset shows the displacement of the parallel twinned calcite crystals that creates tapering of the speleothem toward its tip. Both the dimension of the crystals and the degree of tapering are exaggerated to make the resulting structure evident; B: drawing of the S2 sample consisting of a single dramatically elongated calcite crystal.

Moreover, the relatively small volume increases suggest that for much of the time, the water flowed over the samples with an extremely low supersaturation with respect to calcite, allowing only a scarce epitaxial growth of a few, relatively large crystals. The extremely low tapering angle of the pyramidal stalactites is in perfect agreement with this hypothesis.

It is highly probable that the feeding solution also experienced several periods of simple saturation (no overall solution capacity with respect to $\mathrm{CaCO}_{3}$ ), allowing only the simultaneous exchange of equivalent amounts of ions from solid to liquid and vice versa that caused the progressive enlargement (cannibalism) of a few crystals, while the smaller ones - being more easily dissolved - progressively disappeared. In this respect, the square pyramidal stalactites must be considered the limit crystal structure developing when the external feeding solutions are characterized by a $\mathrm{CaCO}_{3}$ content swinging from extremely low supersaturation to neutral or even extremely low undersaturation.

At least theoretically, square pyramidal stalactites can develop in relatively stable conditions, but this is not the case for the parallelepiped ones: in fact, stationary conditions cannot explain a constant deposition rate from top to tip of the former soda straw. The observed constant sectional areas can be maintained only if the overall balance between periods of under-saturation and super-saturation is in approximate equilibrium (with a slight prevalence of supersaturation to justify the slight increase of volume observed in all the analyzed samples) and if for most of the time, only saturated (neutral) solutions are in contact with the soda straw surfaces.

Therefore, to transform a tubular soda straw into a square parallelepiped, it seems necessary that two strict boundary conditions are met simultaneously: 
1. A film of water flowing very slowly, or even sometimes being stationary, over the whole external surface of the tubular soda straw must be maintained for a rather long interval of time. This is required to allow the slow process of progressively transforming the calcite crystal lattice of the tubular straw into a single, elongated euhedral rhombic crystal.

2. The concentration of calcium carbonate in this water must regularly fluctuate from slightly under-saturated to slightly super-saturated, never varying significantly in either direction. This is required to avoid fast dissolution that may severely damage the outer surface of the mono-crystal, or fast deposition that, in turn, may allow the evolution of several embryonic crystals with different orientation and disrupt the monocrystalline structure.

But these two boundary conditions alone cannot justify the resulting constant size of the square soda straw along its growing axis instead of the more common pyramidal shape, in which the size of the soda straw decreases as it nears the tip. Same size means that a constant supersaturation is maintained along the whole speleothem, but this seems to be in conflict with the fact that local deposition will necessarily deplete the solution in calcium carbonate and therefore the supersaturation must decrease from the top to the bottom of the speleothem (as normally occurs with the conical or even pyramidal stalactites). Condensation is the only water source that can allow such behavior (being at the beginning necessarily undersaturated with respect to calcite). Therefore, the third boundary condition is:

3. External feeding water mostly (if not totally) coming from condensation processes.

Most of the condensation will naturally occur on the ceiling of the cave passage; therefore the subsequent slow seepage toward the top of the squared soda straws will produce a solution of $\mathrm{CaCO}_{3}$ that can sometimes also bring, if the condensing process is slow enough, the water to a complete saturation before reaching the top of the straws. In rare periods of extremely scarce condensation or enhanced evaporation, the seeping water may eventually become even more supersaturated before reaching a straw's top. Obviously, condensation will occur, with different intensities over the whole external surface of the straws, thus locally lowering the $\mathrm{CaCO}_{3}$ concentration. The presence of several small voids along the mean cleavage planes within the monocrystalline structure of the square soda straws, as well as larger re-dissolution features, such as the lens-shaped cavities (Fig. 4), confirms that aggressive water must have been in contact with the external surfaces of at least some of the square soda straws during their development.

The $A$ and $B$ axes of the rhombic crystals forming the square speleothems are not of equal length; the rhombic cross sections show that the lateral increases in soda straw widths or diameters were not homogeneous, and one axis always grew faster than the other (Table 1 and Fig. 9).

This phenomenon is probably a consequence of air currents inverting their directions twice a year, thus causing selective alternations of enhanced condensation and/or evaporation, while the $\mathrm{pCO}_{2}$ of the cave atmosphere undergoes slight variations during the year. The cave is known for its breezes, and air moves upstream during the summer and downstream during the winter throughout the cave. This behavior is consistent with feeding waters supplied by condensation processes, which are higher but with a lower level of $\mathrm{pCO}_{2}$ during the cold and wet seasons (winters), while evaporation prevails during the warmer and drier ones (summer) when the $\mathrm{pCO}_{2}$ is higher (c.f. Banner et al., 2007). Therefore, the transformation from rounded to quite or even totally parallelepiped was mainly induced by the solution-redeposition and recrystallization of the already formed speleothem, while the precipitation of new calcite played a second-order role.

These pieces of evidence confirm that the external water films must flow very slowly or even sometimes be stationary, thus allowing deposition or solution processes to occur, even if calcite saturation levels of the feeding solution change very little. In fact, only extremely low supersaturation can induce an epitaxial growth over the pre-existing monocrystalline structure of the speleothem. In this manner, the soda straw is obliged to gradually transform its cross section from round to rhombic, as required by the crystalline structure of calcite.

However, if the degree of supersaturation is not constant along the whole surface, necessarily the soda straw will become larger at its top and progressively narrow towards its tip as downward movement and precipitation progressively decrease the calcium carbonate content of the solution. This is not the case of the parallelepiped straws. At least some of the time, the upper part of the speleothem must be in contact with slightly undersaturated water that progressively increases its carbonate concentration by solubilizing part of the already existing tube's external structure during its slow motion downward. This temporal variation of the extent of the undersaturated area along the soda straw is consistent with the near constant horizontal cross section dimensions along the $C$ axis of the whole speleothem.

It would be hard to justify this complex behavior by the arrival of seepage water over the external surface of the tube at its attachment point, but this may be compatible with active condensation that always brings undersaturated water in contact with a speleothem's surface. In fact, the normal change in intensity and location (preferred direction) of these phenomena during the year, moving, expanding or reducing the respective areas of under-saturation and oversaturation, can easily explain such in-time and -space variations (Fig. 10).

The relative rarity of parallelepiped soda straws relative to the already very rare pyramidal straws is probably caused by the unique combination of variables required for them to grow. Development of parallelepiped soda straws requires 

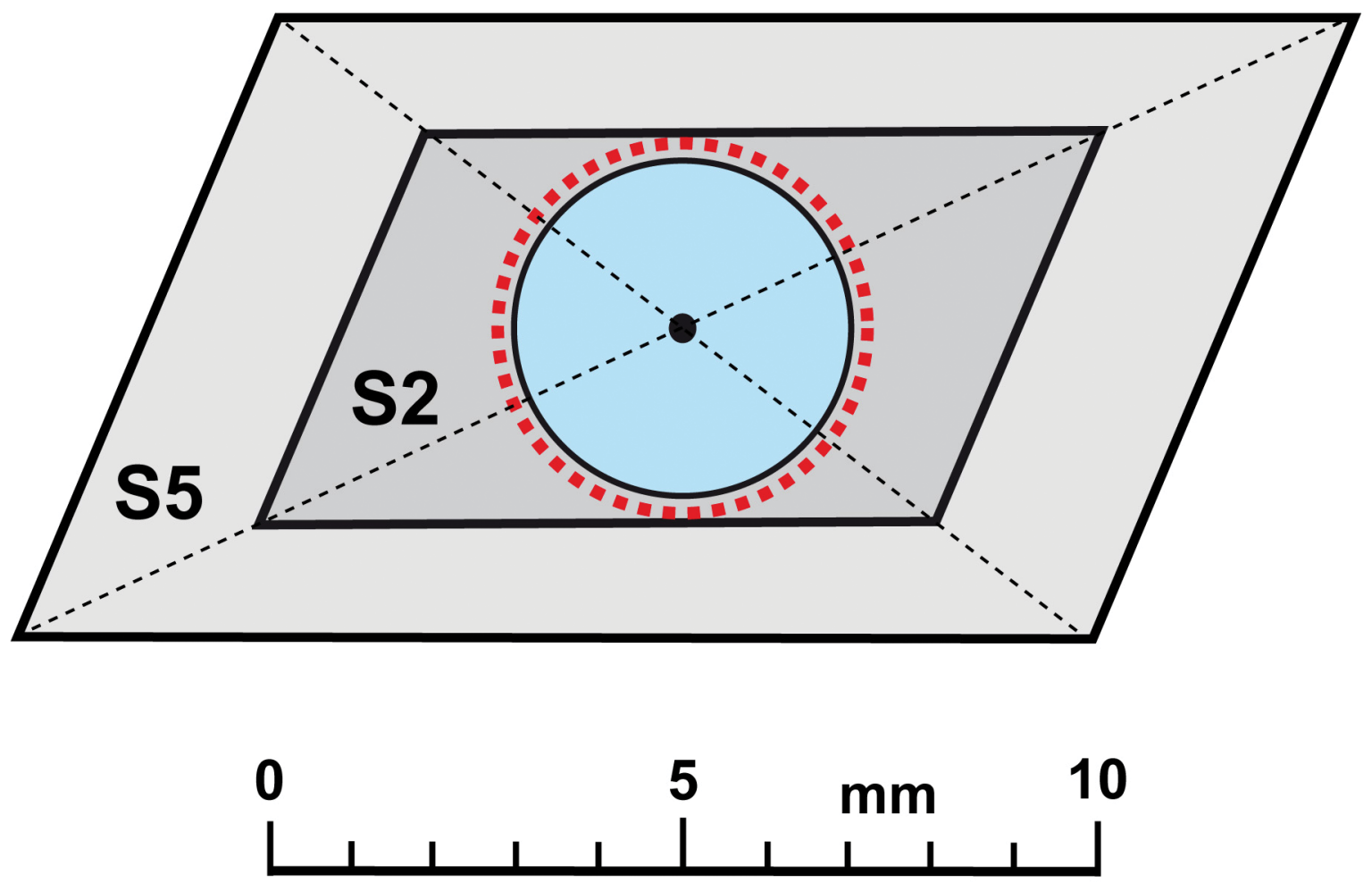

Figure 9. The rounded section of a normal soda straw (red dots) compared with those of the largest (S5) and the smallest (S2) available samples. The blue circle represents the feeding tube of S5, while the black one is that of S2.

air current-driven changes in condensation/evaporation processes that are unique to each speleothem because local air currents are dependent upon the baffling effects of surrounding speleothems and wall geometries. These conditions presumably supplied the necessary variability in time and space of the degree of saturation and feeding rate. In addition, we noticed that if the condensation on a tubular soda straw's $0.1 \mathrm{~mm}$-thick external walls is maintained in the same area for enough time, a hole will be produced, and feeding water would spill out from the internal tube, thus end growth as a typical soda straw.

The final step in the development of the sampled square soda straws was the partial masking of their rhombic shapes by thin, uneven layers of polycrystalline calcite (Figs. 3C and 4). This final stage may have started prior to their falling to the cave floor but probably developed after breakage as the fragments sat on the still-growing flowstone. This final stage was characterized by a sudden increase in supersaturation, which induced new nucleation processes and creation of the thin layers of polycrystalline calcite with palisade structures. This overgrowth partially masked the monocrystalline structure of the speleothem and cemented a few of them to the flowstone floor. This outer crust is very thin (never exceeding 2-3 mm) and suggests this last stage was relatively short. Nonetheless, the achieved supersaturation must be far higher than that in the previous stages, which was always characterized by monocrystalline deposit.

\section{Final remarks}

The square soda straws recently found in the Dry Cave are sub-types of stalactites that can be subdivided into two different groups: pyramidal and parallelepiped ones. Their rhombic cross sections and tapering angles distinguish them from normal conical stalactites and from each other. Typical stalactites are characterized by a tapering angle normally ranging between $3^{\circ}$ and $5^{\circ}$ (Fig. 11). The pyramidal ones are the limit structure for this type of speleothem when supersaturation is kept to a minimum under stationary conditions. This limit is characterized by a tapering degree close to $1.6^{\circ}, 2-3$ times lower than that of the normal stalactites. Only non-stationary conditions may justify the development of quasi- to true-parallelepiped soda straws, characterized by a tapering degree 5-10 times lower than the pyramidal ones 


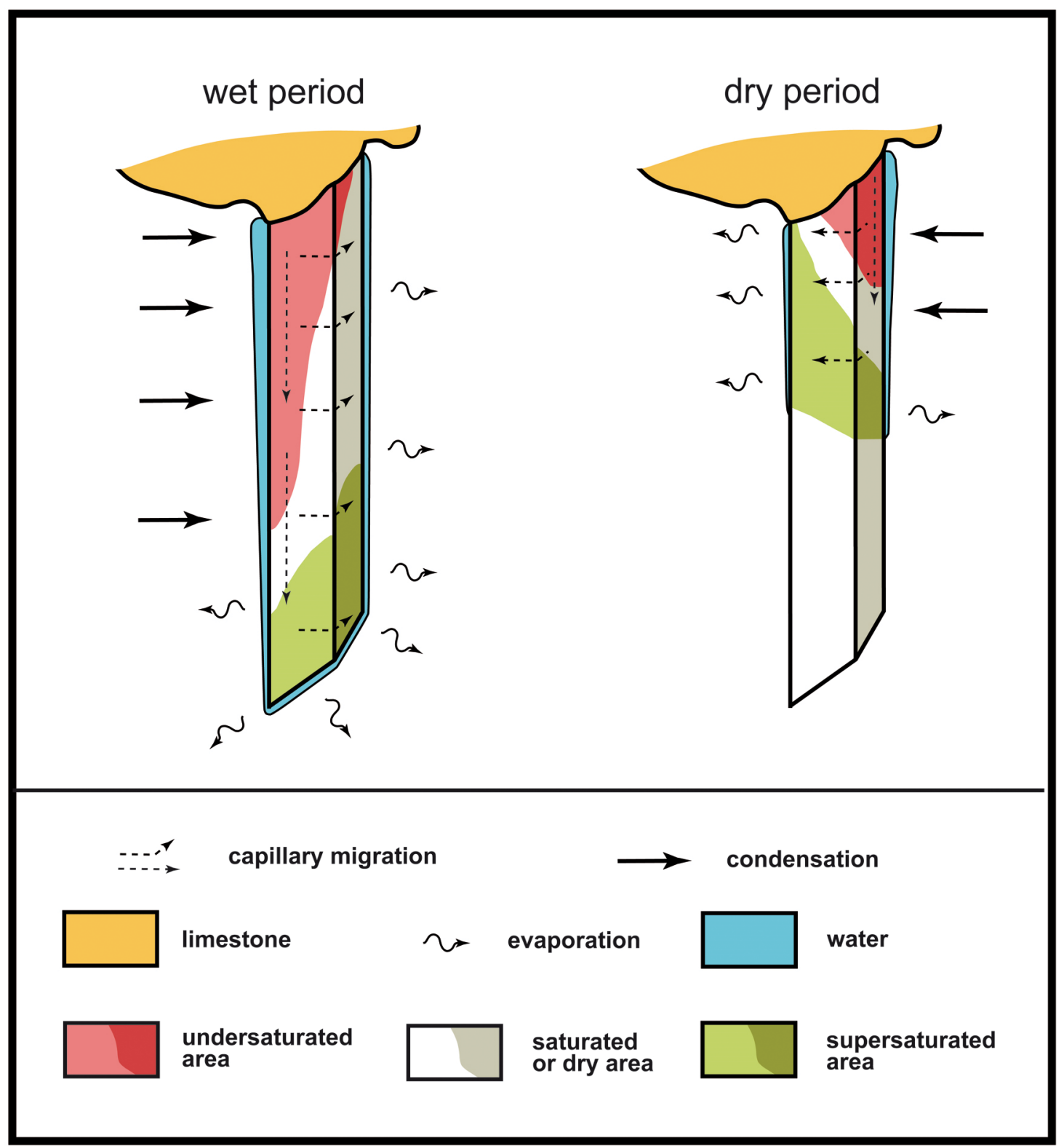

Figure 10. Sketch of two of the possible migrations of the different saturation areas over a square soda straw as a function of the wind direction because it controls the most-likely locations of condensation and evaporation.

$\left(0.3^{\circ}-0.1^{\circ}\right)$. In fact, very peculiar hydro-dynamical and hydro-chemical conditions are required to justify the genesis of the parallelepiped soda straws. Firstly, it is necessary for a film of condensation water to flow very slowly, or even sometimes be stationary, over the external surface of a tubular straw for a rather long interval of time. Moreover, the concentration of calcium carbonate in this water must regularly fluctuate from slightly under-saturation to slightly supersaturation, never raising or lowering to a significant degree in either direction. This is required to maintain the process of solution/re-deposition, which slowly transformed the previous rounded monocrystalline structure into an elongated, single euhedral crystal with a rhombic cross section.

A factor which may easily allow slight swing of the semi-stationary saturation condition is the $\mathrm{CO}_{2}$ content in the cave atmosphere, which is normally subject to slight changes every 12 hours (from day to night and vice versa) and seasonally to a greater extent (from winter to summer). The diffusions from air to water and the reverse are extremely fast processes; thus, even a small change in the partial pressure of $\mathrm{CO}_{2}$ is immediately reflected in the carbon dioxide concentration of stationary or slowly moving water films, which in turn affects the saturation degree with respect to calcite. Presently no data are available on $\mathrm{CO}_{2}$ content and its possible daily or seasonal variation(s) within Dry Cave. Therefore, it is impossible to state if this parameter is really the principal or at least one of those controlling the evolution of the parallelepiped soda straw even if this seems to be quite reasonable. 


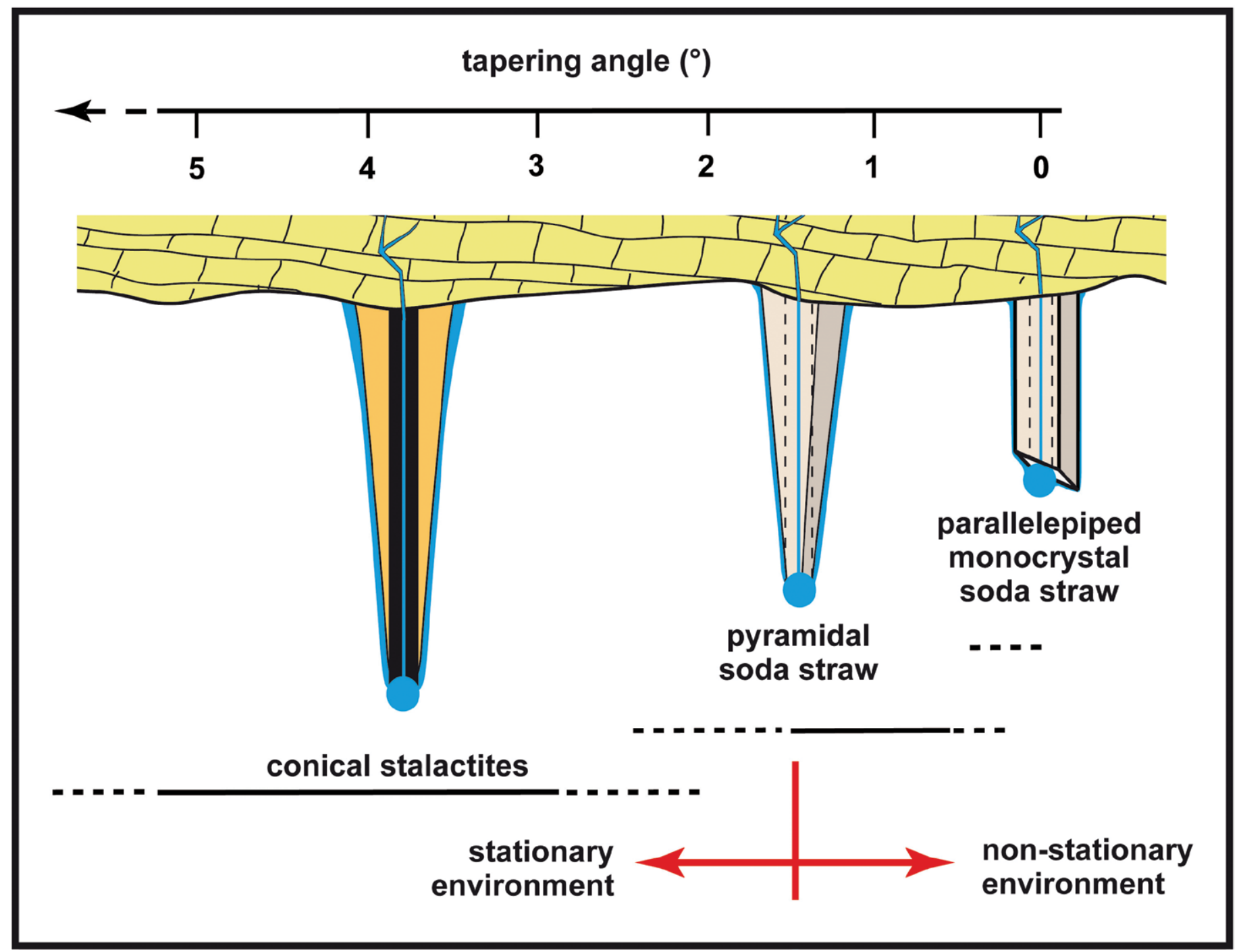

Figure 11. Stalactite sub-types are, in large part, defined by the tapering degree. Conical stalactites have tapering angles greater than $2.5^{\circ}$ and commonly in excess of $5^{\circ}$. Pyramidal square soda straws have tapering angles of $0.1^{\circ}$ to $2.0^{\circ}$, but for tapering values lower than $1.6^{\circ}$, a non-stationary environment is probably required. Finally, the perfect parallelepiped stalactites, first reported herein, are the end member with a tapering angle of $0^{\circ}$ (null).

In the future, the role of $\mathrm{CO}_{2}$, but also our principally speculative genetic mechanism, should be confirmed by experimental measurements carried out on site. The area where the square straws are growing should be continuously monitored not only to achieve the in-time evolution of the local microclimatic data (temperature, relative humidity, $\mathrm{pCO}_{2}$, direction and intensity of air movements, etc.). Moreover, temporal migrations of undersaturated, saturated and supersaturated areas should be monitored over the external surface of these speleothems by means of some chemical analyses.

In any case, it must be noted that 20 years ago the common feeling was that all speleothem types and subtypes were known (Hill and Forti, 1997). However, only stationary conditions were taken into consideration to define their genesis, and it is now recognized that non-stationary conditions can produce a diverse array of sub-types not previously known or expected. In the last few years, explorations made in remote corners of our planet have resulted in documentation of novel speleothems, most of them displaying characteristics that could only have arisen under non-stationary conditions (Camporeale and Ridolfi, 2012; Vesipa et al., 2015; Forti et al., 2016; Badino et al., 2017; Calaforra and Forti, 2019).

These new findings suggest that the underground world is much more complex than supposed; and therefore, it is highly probable that in the next few years, new strange speleothems will be discovered, or some of those, presently supposed to be exclusive of a single cave, will eventually reveal to be rather common. This shows that the study of caves and speleothems will remain a research field full of discovery and satisfaction for cavers who devote themselves to it. 


\section{Acknowledgments}

The authors thank Prof. Paolo Garofalo of the Biological, Geological and Environmental Sciences Department of the University of Bologna for the microscope analyses of the thin sections of the square soda straws and Prof. Jo De Waele of the same Department for the useful discussions. We thank the West Virginia Association for Cave Studies for providing logistical and field support and the Cave Conservancy of the Virginias for funding future work in the cave. Finally, we thank Benjamin Schwartz and a second anonymous referee for the help given in improving the manuscript. Figure 1 photo courtesy of David Socky; Figure 2A photo courtesy of Nikki Fox.

\section{References}

Badino, G., Calaforra, J.M., De Waele, J., and Forti, P., 2017, An Hypothesis On The Evolution of Complex Flowstones, in Proceedings $17^{\text {th }}$ International Congress of Speleology, Sydney, v. 2, p. 320-324.

Banner, J.L, Guilfoyle, A., James, E.W., Stern L.A., and Musgrove, M., 2007, Seasonal variations in modern speleothem calcite growth in Central Texas, U.S.A.: Journal of Sedimentary Research, v. 77, no. 8, p. 615-622. https://doi.org/10.2110/jsr.2007.065.

Basset, W.A., and Basset, A.M., 1962, Hexagonal stalactite from Rushmore cave, South Dakota: National Speleological Society Bulletin, v. 24, p. 88-94.

Calaforra, J.M., and Forti, P., 2019, The climate driven peculiar speleothems of the Natuturingam Cave (Puerto Princesa Underground River, Palawan, Philippines): a review: Atti e Memorie Comm. Grotte E. Boegan, v. 48, p. 3-22.

Camporeale, C., and Ridolfi, L., 2012, Hydrodynamic-driven stability analysis of morphological patterns on stalactites and implications for cave paleoflow reconstruction: Physical Review Letters, v. 108, p. 238501 https://doi.org/10.1103/PhysRevLett.108.238501.

Curl, R.L., 1973, Minimum diameter of stalactites: National Speleological Society Bulletin, v. 34, no. 4, p. 129.

Fairchild, I.J., and Baker, A., 2012, Speleothem Science: From Processes to Past Environments: West Sussex, UK, Wiley-Blackwell, 432 p. https://doi.org/10.1002/9781444361094.

Forti, P., Badino, G., Calaforra, J.M., and De Waele, J., 2016, The ribbed drapery of the Puerto Princesa Underground River (Palawan, Philippines): morphology and genesis: International Journal of Speleology, v. 46, no. 1, p. 93-97. https://doi.org/10.5038/1827-806X.46.1.2011.

Franke, H.W., 1965, The theory behind stalagmite shapes: Studies in Speleology, v. 1, no. 2/3, p. 89-95.

García-Ruiz, J.M., Villasuso, R., Ayora, C., Canals, A., and Otálora, F., 2007, Formation of natural gypsum megacrystals in Naica, Mexico: Geology, v. 35, p. 327-330. https://doi.org/10.1130/G23393A.1.

Halliday, W.R., 1959, Holocrystalline Speleothems: National Speleological Society Bulletin, v. 21, p. 15-20.

Hill, C.A., and Forti, P., 1997, Cave Minerals of the World: National Speleological Society, $424 \mathrm{p}$.

Mullin, J.W., 1997, Crystallization, $3^{\text {rd }}$ ed.: London, Butterworth-Heinemann, 527 p. https://doi.org/10.1002/cite.330701126.

Price, P.H., and Heck, E.T., 1939, Greenbrier County: West Virginia Geological Survey County Reports, 846 p.

Short, M.B., Baygents, J.C., and Goldstein, R.E., 2005a, Stalactite growth as a free-boundary problem: Physics of Fluids, v. 17 , no. 8, p. 083101. https://doi.org/10.1063/1.2006027.

Short, M.B., Baygents, J.C., Beck, J.W., Stone, D.A., Toomey III, R.S., and Goldstein, R.E., 2005b, Stalactite growth as a free-boundary problem: a geometric law and its platonic ideal: Physical Review Letters, v. 94, no. 1, p. 018501. https://doi.org/10.1103/PhysRevLett.94.018501.

Springer G., 2019, Dry Cave: Beyond the Bitter End, The West Virginia Caver, v. 37, no. 4, p. 3-4.

Vesipa R., Camporeale C. and Ridolfi L., 2015, Thin-film-induced morphological instabilities over calcite surfaces, in Proceedings Royal Publishing Society A, v. 471, no. 2176, p. 20150031. https://doi.org/10.1098/rspa.2015.0031

White W.B., 1976, Cave minerals and speleothems, in Ford T.D., Cullingford C.H., eds., The Science of Speleology: London, Academic Press, p. 267-327. 